\title{
Psychological Effects of Labor Gymnastics Program in Office Workers
}

\author{
Maria Luana Reis Santos, Martha Maria Viana de Bragança, Ricardo Fontes Macêdo*, Robelus De Bortoli, Wendel \\ de Oliveira Mota Ribeiro, Camila Souza Vieira and Manuella de Oliveira Mota Fernandes \\ Sergipe Federal University, Brazil
}

*Corresponding author: Ricardo Fontes Macêdo

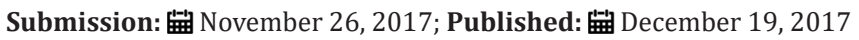

\begin{abstract}
There are times that industries seek alternatives to improve the productivity of your employees. With the advancement of technology, entrepreneurs needed to do scales of its employees in large quantity so that there was financial return for your business. With this practice, the staff began to show some lesions not detected as diseases. The objective of this study is to assess the psychological effects of Labor Gymnastics in office workers Aracaju, practitioners and non-practitioners. This study presents characteristics of a cross-sectional study. The population of this research consists of individual office workers Aracaju, SE. The sample will consist of 15 individuals, of both sexes, all workers in a national office telecommunications, with a regional unit in Aracaju, SE. Will use the STAI questionnaire (Inventory of state-trait anxiety), developed by Spilberger et al. in 1966.
\end{abstract}

Keywords: Cumulative trauma disorders; Workers; Social behavior

\section{Introduction}

The Labor Gymnastics (LG) consists of stretching exercises, muscle strengthening, motor coordination and relaxation. It can be performed in different work environments in order to prevent diseases caused by repetitive efforts [1]. Silva and Salate report the LG as a preventive and therapeutic instrument in the health area, providing improvements in pain, stress, boredom and occupational diseases caused by repetitive efforts during the work. The Repetitive Stress Injuries (RSI) or Musculoskeletal Disorder (MSD) can affect, tendons, muscles, nerves, fascias and ligaments, in association with or without tissue degeneration, where, mainly, the upper limbs like scapula and neck are affected. An injury or disorder may cause failure to the worker as tremors, lack of coordination, inability to handle objects, stiffened joints and difficulties to perform precise movements among others [2].

The LG is performed on-site with duration of five, ten or fifteen minutes, having as goal the prevention of RSI/MSD and reduce stress, freeing individuals of these symptoms through the stretching and relaxation exercises [1]. Over the years, the LG had significant modifications to workers; it sought to provide them an improvement in their performance, thus creating a sharp interest in Gymnastics programs [3]. The practice of Calisthenics can generate in such benefits as increased blood circulation and muscle oxygenation by improving breadth and flexibility of joints, improves concentration, prevention of RSI/MSD, improvement of morale, willingness to work, improves the reflexes to prevent accidents, development of body awareness and reduced mental fatigue, among others [3].

In the research with the implementation of the program of gymnastics, from three months to a year in a company, it had many benefits for employees as the decrease of the RSI/MSD, lower cost with medical assistance, reduction of body aches, reduction of faults in the work, improvement in the lifestyle of employees and companies reflected in increased productivity [1]. Under this perspective, anxiety is considered a warning sign, determined by the presence of an internal conflict, whose job is to warn about an imminent danger in order to take measures to deal with the threat [4]. With the advancement of technology workers over time has been suffering with various diseases, one of these is the anxiety and the LG has as a goal to improve the conditioning of these workers [3].

During the course of time, entrepreneurs began to be concerned about the increase of employees injured on the job, as they only aimed at the profit of their company, they realized they would have to do something different not only for the business but also for the employee, thus the labor gymnastics program was implemented [3]. Thereby, the following question arises: Is the Labor Gymnastics is contributing to improving the welfare of the employees of the offices in Aracaju? Considering this, this study sought to compare the psychological effects of LG and what the program has provided for office workers.

\section{Material and Methods}

\section{Search type}

This is a cross-sectional descriptive study. The researcher needs to have a direct contact with the environment, in addition to investigating, will assess and highlight the meanings of the data found in the context of reality. 


\section{Population and sample}

In order to create the sample, criteria of inclusion and exclusion were created, therefore, the Office Worker Gymnastics Practitioners (TEPGL), should stay, at least, three months in the program of Gymnastics in the office. The ones who attended for three months, twice a week, regularly, during all weeks, hours per session and as a criterion for deletion, does not missed more than $20 \%$. The population of this research consists of 14 individuals of the National Bureau of tele-communications; a regional unit in Aracaju/SE, practicing LG, with 5 women and 9 men, the minimum age is 21 years and a maximum of 54 years.

\section{Instruments and materials}

The questionnaire of STAI (State-Trait anxiety Inventory) was used. The State-Trait anxiety Inventory was developed by Spilberger et al. in 1966 with the purpose to develop a scale only to analyze State and trait anxiety [5]. For this work, the questionnaire was divided into two parts; the first individuals will respond what they are feeling at that exact moment, a compilation of 20 questions that comes with four options for answers divided into (1) absolutely not, (2) a little, (3) enough, (4) a lot. In the second part of the questionnaire, individuals will respond how they were feeling 10to 15 days before the questionnaire, a compilation of 20 questions also divided into four options for answers that are (1) almost never, (2) sometimes, (3) often, (4) almost always. The data will be tabulated in a Microsoft Excel spreadsheet.

\section{Procedures for data collection}

The project was submitted to the Ethics Committee and research was presented to the Board of Directors of the National Telecommunications Company. After the approval, the study was forwarded for presentation to employees practitioners of LG. The following measures have been adopted, the participation will be voluntary and free will, the anonymity was guaranteed, the information received will be kept secret, will be archived and will be used only for scientific purposes, and the results will be published for the need to sign an informed consent, containing all the necessary information about the study, which will be read in addition to the researcher to clarify any doubts that might have at the time of signature of that term.

The study's data collection was carried out from October to November of 2013. The questionnaires to obtain the results were applied during these two months. The time required for the implementation of this instrument will be, on average, 5 to 10 minutes, and will be applied by the researcher in the best moment for the volunteers. The collected data are recorded in a spreadsheet built for this purpose for statistical analysis.

\section{Statistical analysis}

A descriptive analysis was made consisting of media and standard deviation using the student's $t$ test for independent samples.

\section{Ethical care}

This search was not an invasive study. Before join in this project, volunteers received all the information about the goals and methodology of the study process, signed a written consent form and were aware that, at any time, could no longer participate in the research. Every precaution was taken in order to preserve the privacy of the volunteers, and the health and well-being of these should and will be above any other interest.

\section{Results}

The following results of the research show the STAI (StateTrait Anxiety Inventory) of individuals investigated in comparison with other studies, including the analysis, marital status, education level and intensity of pain with your daily tasks including at work. In Figure 1 presents the marital status of the practitioners of LG program in office workers of Aracaju (TEPGL), which was 21\% for single individuals and $79 \%$ for married.

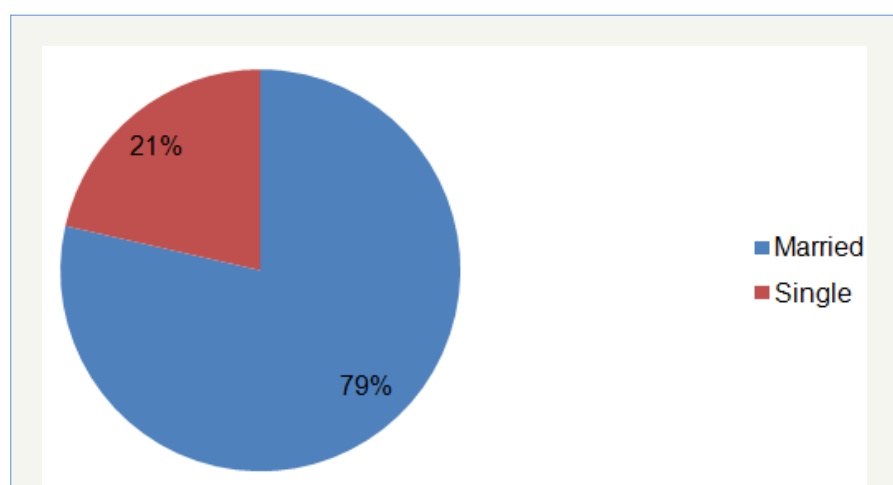

Figure 1: Individuals's marital status.

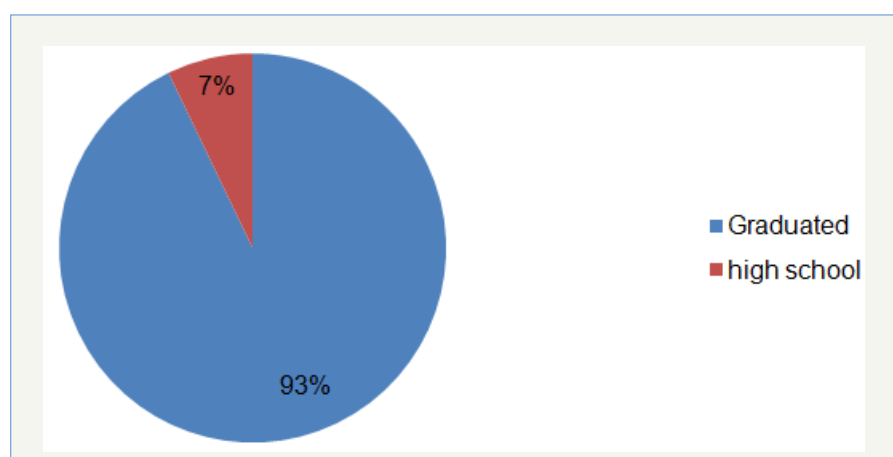

Figure 2: Educational level.

The Figure 2 presents the level or degree of education of workers practitioners of LG program in offices of Aracaju (TEPGL), $7 \%$ has High School education, and 93\% has bachelor degree. These results were due to the function that each exerts on the company it is necessary to have a bachelor degree.

The Figure 3 did a statistical analysis of the average and standard deviation of the pain level of workers practitioners of LG program in offices of Aracaju (TEPGL), where the degree of pain was zero (0) to ten (10), the arm was averaging 2.43 with standard deviation 2.93, wrist/hand 2.50 with the average standard deviation of 3.11, neck 3.0 with the average standard deviation of 2.99 , back 4.14 and average standard deviation of 3.18 , legs was 3.07 with the average standard deviation of 2.27 . 


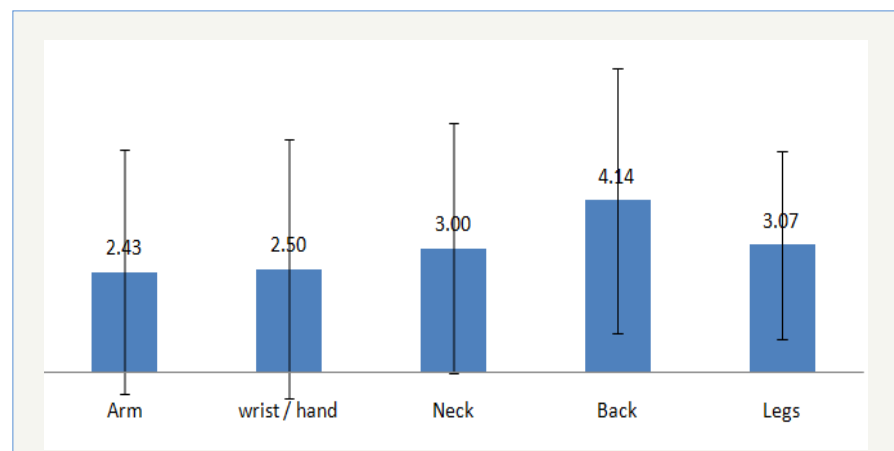

Figure 3: The average and standard deviation of the pain level of workers practitioners of LG program in offices of Aracaju.

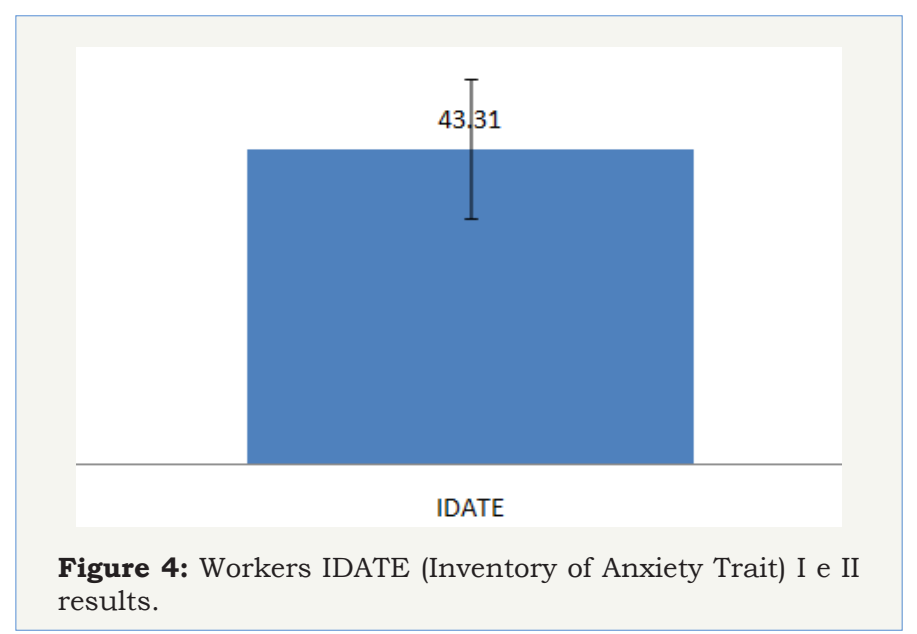

In Figure 4 shows the average STAI, where the STAI has an average level of anxiety that goes 20 to 80, over these levels, the anxiety reaches the extreme of individuals analyzed. However, the State Anxiety Inventory (STAI) was 40.9 and the Inventory of Anxiety Trait (IDATE), was of 43.0 (Table 1).

Table 1: Average of the results of the IDATE I and II quoted in literature.

\begin{tabular}{|c|c|c|c|c|c|c|}
\hline & \multirow{2}{*}{ TEPGL } & GMama & GPlast & \multicolumn{3}{|c|}{ Aracaju } \\
\cline { 5 - 7 } & & $\begin{array}{c}\text { Minor } \\
\mathbf{3 0}\end{array}$ & $\mathbf{3 0}$ to $\mathbf{4 5}$ & $\begin{array}{c}\text { Largest } \\
\mathbf{4 5}\end{array}$ \\
\hline $\begin{array}{c}\text { IDATE } \\
\text { (I) }\end{array}$ & 43 & 42.3 & $38.0^{*}$ & & & \\
\hline $\begin{array}{c}\text { IDATE } \\
\text { II }\end{array}$ & 40.9 & 39.1 & 37.6 & 41.8 & $37.5^{*}$ & 39 \\
\hline
\end{tabular}

${ }^{*} \mathrm{p}<0.05$

Through the t-Student test a sample against the population (one-sample t-test), a significant difference was found $(\mathrm{p}<0.05)$ the average points obtained from the IDATE I parsed TEPGL Group (media=43.0) and GPlast Group (media=38.0) and in the average of the points obtained from the IDATE II the Group analyzed (media $=40.9$ ) and academic group of Aracaju aged between 30 and 45 years (media=37.5). On average, the group analyzed has increased anxiety state than the Gplast and had higher anxiety that than the trait academics of Aracaju aged between 30 and 45 years.

\section{Discussion}

This study aimed to verify the psychological effects of workers practitioners of LG program in office of Aracaju. The main results showed that the level of the anxiety state was 43.0, relatively high compared to other studies using the same procedures, and the anxiety trait was elevated to 40.9 with the analysis of other studies [6]. In study using the STAI (State-trait Anxiety Inventory) each with 20 questions, where the STAI (State Anxiety Inventory) is characterized at the moment, i.e., how the individual feels in that moment, the STAI (Trait Anxiety Inventory), is how the individual feels normally. The study was composed by 114 individuals who would go through surgery, breast surgery and aesthetic, being the Gmama and Gplast. It was observed that the STAII, which the classification of low state anxiety is: $\leq 35$, moderate 46 to 36 and high $\geq 42$. The Anxiety State classified as STAIII, the low anxiety was, $\leq 32$; moderate anxiety 33 to 41 ; high anxiety $\geq 42$. In order to obtain those results was used SPSS Windows program 14, medium and standard deviation, median, $\mathrm{t}$ Student test for statistical analysis of the results. Anxiety State (STAI) was observed where significant difference $(p=0,043)$, however the anxiety trait (STAI), there was no significant difference $(\mathrm{p}=0,776)$. The study analyzed TEPGL, it was verified that Anxiety State was 43.0 compared to G plast of 38.0. These results report about the long working days and overtime of the individuals in their workplace, thus causing muscle discomfort and affecting the well-being of individuals [7].

Another study gathering 498 individuals 231 men and 267 women, college students aged between 30 and 45 years in a study using only the anxiety trait STAI(Trait Anxiety Inventory) being that this score is between 20 and 80 points, knowing that these higher values increased the anxiety level of individuals investigated [8]. In the study, women showed higher scores compared to men, for analysis of the data was verified average, standard deviation and percentage and the thesis $t$ of Student. It was also highlighted that with individuals with up to 30 years showed higher trait anxiety that individuals between 31 and 45 years. This study has also been compared to another study conducted in the city of São Paulo with 1080 students, whose scores of smaller STAI trait was found in students from Aracaju, where the highest level of anxiety was on single women over 30 years old with 37.5 [8].

In the study that analyzed the anxiety trait, it was relatively high in comparison to the study of college students of Aracaju where the anxiety trait was 37.5 and TEPGL was 40.9 . These factors with the highest level of anxiety trait is due to the fact the tele service, in which individuals feel pressed to the rhythm of the customer, they are required to work a longer period of time, on the other hand the company requires a time of customer service [9]. To investigate the relationship between State Anxiety and Anxiety State (STAI) and vocal parameters, with 24 individuals of both sexes, 12 men and 12 women aged between 19 and 42 years, participants were split into two groups: low anxiety (LA) and High anxiety (HA) of STAI, where it was observed that in the lower intensity STAI was of $35 \pm 4.3$ and high intensity $55.5 \pm 9.1$. The higher the anxiety trait shown by STAI, 
the greater the evidence of anxiety in speech and chained in the speech, the higher the anxiety State, the greater evidence of anxiety in several parameters of the speech, with imbalance in vocal resonance, commitment to modulation, in articulation of speech and facial expression [10].

\section{Conclusion}

With the results obtained can see that the TEPGL, has a higher level of anxiety in comparison to other studies using the same methods. Thus, it can be considered that the practice of LG, there were no significant differences in the results of the tests of anxiety in practitioners of LG program in office workers of Aracaju.

Through research, it was realized that the needs of workers to smooth the long journey that exceeds the limit of their work schedule, which is faced by the workers in their day-to-day being an obstacle that may interfere with their performance, are features for their high anxiety. The LG held in that studied group, with its little runtime in the company, consisting of only 15 minutes, as recommended, and as is not being performed by the workers daily in their workday entails an unsatisfactory result on the studied group.

\section{References}

1. Oliveira JRG (2007) A importância da Ginástica laboral na prevenção de doenças ocupacionais. Revista de Educação Física 139: 40-49.
2. Silva JB, Salate ACB (2007) A ginástica laboral como forma de promoção à saúde. Fisioterapia e Especialidades 1(1): 15-19.

3. Ferreira MT, Robson WC (2012) Ginástica laboral da educação física escolar: um estudo de caso da escola CINTRA-Centro de Integração Rio Anil. Revista Sapientia.

4. Ferreira CL, Almondes KM, Braga LP, Sousa Mata AM, Lemos CA, et al. (2009) Universidade, contexto ansiogênico? Avaliação de traço e estado de ansiedade em ciclo básico. Revista Ciência \& Saúde Coletiva 14(3): 973-981.

5. Kaipper MB (2008) Avaliação do Inventário de ansiedade traço-estado (IDATE) através da análise de Rasch.

6. Gozzani JL, Mathias SA, Marcolino JM, Guaratini A (2007) Ansiedade no período pré-operatório de cirurgias de mama: estudo comparativo entre pacientes com suspeita de câncer e a serem submetidos a procedimentos cirúrgicos estéticos. Revista Brasileira de Anestesiologia 57(2): 147-156.

7. Candotti CT, Silva MR, Noll M, Lucchese CR (2011) Efeito da ginástica laboral sobre a motivação para a prática regular de atividade física. Revista Baiana de Saúde Pública. 35(2): 485-497.

8. Gama MMA, Moura GS, Araújo RF, Silva FT (2008) Ansiedade-traço em estudantes universitários de aracaju (SE). Revista de Psiquiatria do Rio Grande do Sul 30(1): 19-24.

9. Soares RG, Assunção AA, Lima FdPA (2006) A baixa adesão do programa de ginástica laboral: buscando elementos do trabalho para entender o problema. Revista Brasileira de Saúde Ocupacional 31(114): 149-160.

10. Almeida AAF, Bahlau M, Leite JR (2011) Correlação entre ansiedade e performance comunicativa. Revista da Sociedade Brasileira de Fonoaudiologia 16(4): 384-389. 